\title{
New trends and recent advances in coherent Raman microscopy and nonlinear optical spectroscopy: introduction to the special issue
}

\author{
A. Volkmer, ${ }^{\text {a P. P. Radi, }}{ }^{\text {b }}$ A. M. Zheltikov ${ }^{c *}$ and A. Zumbusch ${ }^{d}$ \\ This special issue highlights 20 papers, presenting the latest theoretical and experimental developments and achievements in \\ coherent anti-Stokes Raman scattering (CARS) microscopy and nonlinear optical spectroscopy. Most of them were presented \\ at the seventh European Conference on Nonlinear Optical Spectroscopy (ECONOS 2008) jointly held with the first European \\ Conference on CARS Microscopy (microCARS 2008) in Igls, Austria, May 25-27, 2008.
}

Keywords: coherent anti-Stokes Raman scattering; nonlinear Raman techniques; four-wave mixing; CARS microscopy; femtosecond pulse shaping

During the last two decades, the quest to generate sample intrinsic image contrast in optical microscopy without the need for sample labeling and the ready availability of pulsed laser sources have led to the introduction of a variety of nonlinear optical excitation schemes for microscopy. These include secondharmonic generation (SHG), third-harmonic generation (THG), and coherent anti-Stokes Raman scattering (CARS). CARS microscopy has been demonstrated to allow vibrational imaging and microspectroscopy with high sensitivity, high spectral resolution, and three-dimensional sectioning capability. ${ }^{[1-3]}$ From the start, the development and application of CARS microscopy has been based upon the vast amount of knowledge collected over nearly five decades of the application of CARS in gas- and condensedphase spectroscopy. ${ }^{[4,5]}$ A discussion forum for the latter is the annual European Conference on Nonlinear Optical Spectroscopy (ECONOS), which is the successor to a series of conferences known for decades as the European CARS Workshop. Meanwhile, the emergence of CARS microscopy has led to the development of a flourishing scientific community and renewed interest in CARS spectroscopy. In order to foster a lively exchange of ideas between scientists with very different scientific backgrounds, the first European Conference on CARS Microscopy (microCARS 2008) was held jointly with the seventh ECONOS 2008 from 25 to 27 May 2008 in Igls, Austria.

The joint meeting offered a representative platform covering the full spectrum of nonlinear optical spectroscopy and the rapidly growing area of the development and application of CARS microscopy. The meeting was attended by more than 120 registered attendees and featured one plenary talk, six invited talks, and more than 70 contributed papers. The conference also included three invited tutorials that provided broader introductions to key topics of the conference. The 16 sessions covered topics including Femtosecond CARS Spectroscopy, CARS/Raman Bioimaging, Multiplex CARS Micro-spectroscopy, CARS Microscopy with Shaped Femtosecond Pulses, Nonlinear Optics of Nanosystems, of Composite Materials, and in the GasPhase, as well as the Theoretical and Experimental Investigation of Signal Generation in Nonlinear Microscopy. The ECONOS conference chair was Monika Ritsch-Marte. MicroCARS was chaired by Andreas Volkmer and Andreas Zumbusch, who are also acting as guest editors of this special issue on behalf on microCARS 2008 together with Peter P. Radi and Aleksei M. Zheltikov for ECONOS 2008.

For this special issue, it was our intention to cover a large variety of the recent advances made in nonlinear spectroscopy and CARS microscopy. Therefore, the topics range from fundamental theoretical aspects of CARS ${ }^{[6-9]}$ to usage of CARS microscopy in noninvasive imaging of living cells, tissues, and materials. ${ }^{[10-12]}$ The long known fact that CARS is also a highly sensitive and informative spectroscopic technique is exemplified in a number of articles. ${ }^{[13,14]}$ A focus here is on CARS as a powerful tool for gas-phase diagnostics and thermometry. ${ }^{[15,16]}$ This special issue bears witness to the fact that spectroscopy in a traditional manner forms the basis of CARS microscopy, whereas advanced schemes derived from the versatility of femtosecond pulse shaping have an increasing impact on both CARS spectroscopy and microscopy. ${ }^{[17-20]}$ The CARS work is beautifully supplemented in this special issue by contributions presenting significant advances in ultrafast nonlinear techniques ${ }^{[21]}$ and four-wave mixing applications and methodology. ${ }^{[22-25]}$

We thank the local organizers of the 2008 ECONOS/microCARS meeting, in particular, our colleague Monika Ritsch-Marte, for

\footnotetext{
* Correspondence to: A. M. Zheltikov, Physics Department, International Laser Center, M.V. Lomonosov Moscow State University, Vorob'evy gory, 119992 Moscow, Russia.E-mail:zheltikov@phys.msu.ru

a $3^{\text {rd }}$ Institute of Physics, University of Stuttgart, Pfaffenwaldring 57, 70569 Stuttgart, Germany

b Department General Energy, Paul Scherrer Institute, CH-5232 Villigen, Switzerland

c Physics Department, International Laser Center, M.V. Lomonosov Moscow State University, Vorob'evy gory, 119992 Moscow, Russia

d Department of Chemistry, University of Konstanz, Fach 722, D-78457 Konstanz Germany
} 
making the Igls conference such a success. This special issue has been made possible by the support of the Editor-in-Chief of the Journal of Raman Spectroscopy, Wolfgang Kiefer, to whom we are indebted for his help. It has been our pleasure and honor to serve as editors for this collection of ECONOS/microCARS papers. We thank all the authors for their efforts in contributing the manuscripts and look forward to the next ECONOS and microCARS meetings.

\section{References}

[1] A. Volkmer, J. Phys. D: Appl. Phys. 2005, 38, R59.

[2] M. Müller, A. Zumbusch, Chem. Phys. Chem. 2007, 8, 2156.

[3] C. L. Evans, X. S. Xie, Annu. Rev. Anal. Chem. 2008, 1, 883.

[4] A. J. Druet, J.-P. E. Taran, Prog. Quantum Electron. 1981, 7, 1.

[5] G. L. Eesley, Coherent Raman Spectroscopy, Pergamon: Oxford, 1981.

[6] C. H. R. Ooi, J. Raman Spectrosc. 2009, 40, 714

[7] Y. Liu, Y. J. Lee, M. T. Cicerone, J. Raman Spectrosc. 2009, 40, 726.

[8] M. Marrocco, E. Nichelatti, J. Raman Spectrosc. 2009, 40, 732.

[9] M. Marrocco, J. Raman Spectrosc. 2009, 40, 741.

[10] C. Brackmann, J. Norbeck, M. Åkeson, D. Bosch, C. Larsson, L. Gustafsson, A. Enejder, J. Raman Spectrosc. 2009, 40, 748.

[11] A. Downes, R. Mouras, A. Elfick, J. Raman Spectrosc. 2009, 40, 757.
[12] M. Bonn, M. Müller, H. A. Rinia, K. N. J. Burger, J. Raman Spectrosc. 2009, 40, 763.

[13] A. G. Caster, S. Kowarik, A. M. Schwartzberg, O. Nicolet, S.-H. Lim, S. R. Leone, J. Raman Spectrosc. 2009, 40, 770.

[14] F. Munhoz, S. Brustlein, D. Gachet, F. Billard, S. Brasselet, H. Rigneault, J. Raman Spectrosc. 2009, 40, 775

[15] Y. Gao, M. C. Weikl, T. Seeger, A. Leipertz, P. Joubert, J. Bonamy, J. Raman Spectrosc. 2009, 40, 781.

[16] A. Bohlin, F. Vestin, P. Joubert, J. Bonamy, P.-E. Bengtsson, J. Raman Spectrosc. 2009, 40, 788.

[17] J.Peng, D. Pestov, M. O. Scully, A. V. Sokolov, J. Raman Spectrosc. 2009, 40, 795.

[18] W. Langbein, I. Rocha-Mendoza, P. Borri, J. Raman Spectrosc. 2009, 40,800 .

[19] C. Müller, T. Buckup, B. von Vacano, M. Motzkus, J. Raman Spectrosc. 2009, 40, 809.

[20] V. S. Malinovsky, J. Raman Spectrosc. 2009, 40, 817.

[21] J. Liebers, A.Scaria, A. Materny, U. Kleinekathöfer, J. Raman Spectrosc. 2009, 40, 822.

[22] J. Kiefer, A. Meyerhöfer, T. Seeger, A. Leipertz, Z. S. Li, M. Alden, J. Raman Spectrosc. 2009, 40, 828.

[23] A. F. Bunkin, S. M. Pershin, J. Raman Spectrosc. 2009, 40, 836.

[24] L. De Dominicis, R. Fantoni, J. Raman Spectrosc. 2009, 40, 840.

[25] X. Chen, T. B. Settersten, A. P. Kouzov, J. Raman Spectrosc. 2009, 40, 847. 